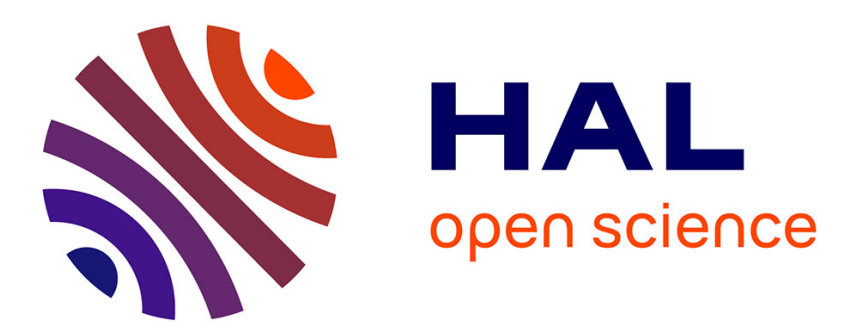

\title{
Effect of Germanium content and strain on the formation of extended defects in ion implanted Silicon/Germanium
}

\author{
Pier-Francesco Fazzini, Fuccio Cristiano, Etienne Talbot, Gérard Benassayag, \\ S. Paul, Wilfried Lerch, A. Pakfar, J.M. Hartmann
}

\section{To cite this version:}

Pier-Francesco Fazzini, Fuccio Cristiano, Etienne Talbot, Gérard Benassayag, S. Paul, et al.. Effect of Germanium content and strain on the formation of extended defects in ion implanted Silicon/Germanium. Thin Solid Films, 2010, 518 (9), pp.2338 - 2341. 10.1016/j.tsf.2009.09.172 . hal01633467

\section{HAL Id: hal-01633467 https://hal.science/hal-01633467}

Submitted on 16 Jan 2019

HAL is a multi-disciplinary open access archive for the deposit and dissemination of scientific research documents, whether they are published or not. The documents may come from teaching and research institutions in France or abroad, or from public or private research centers.
L'archive ouverte pluridisciplinaire HAL, est destinée au dépôt et à la diffusion de documents scientifiques de niveau recherche, publiés ou non, émanant des établissements d'enseignement et de recherche français ou étrangers, des laboratoires publics ou privés. 


\title{
Effect of Germanium content and strain on the formation of extended defects in ion implanted Silicon/Germanium
}

\author{
P.F. Fazzini a,b,*, F. Cristiano ${ }^{\text {a,b }}$, E. Talbot ${ }^{\text {a,b }}$, G. Ben Assayag ${ }^{\text {c }}$, S. Paul ${ }^{\text {d }}$, W. Lerch ${ }^{\text {d }}$, A. Pakfar ${ }^{\text {e }}$, J.M. Hartmann ${ }^{\mathrm{f}}$ \\ a CNRS-LAAS, 7 av. du col. Roche, 31077 Toulouse, France \\ ${ }^{\mathrm{b}}$ Université de Toulouse; UPS, INSA, INP, ISAE; LAAS; 31077 Toulouse, France \\ c CEMES-CNRS, University of Toulouse, 29 rue J. Marvig, 31055 Toulouse, France \\ d Mattson Thermal Products GmbH, D-89160 Dornstadt, Germany \\ e STMicroelectronics, 850 Rue Jean Monnet, 38926 Crolles Cedex, France \\ ${ }^{\mathrm{f}}$ CEA-LETI, MINATEC, 17 Rue des Martyrs, 38054 Grenoble Cedex 9, France
}

\begin{abstract}
A B S T R A C T
We studied the evolution of extended defects in relaxed and strained Si and SiGe structures after an amorphising implant. The investigated structures included three relaxed SiGe alloy layers with various Ge contents (20, 35 and 50 at.\%), a 40 nm-thick tensely strained Si layer and a 40 nm-thick compressively strained $\mathrm{Si}_{088} \mathrm{Ge}_{02}$ layer. Concerning the compositional effects, we found that the increase of Ge concentration in relaxed SiGe structures leads to: (i) an overall decrease of the defect stability and to (ii) an enhanced \{311\}-to-loops transformation. As for the strain effects, it is found that: (i) Tensile strain (in Si) retards the transformation of $\{311\}$ defects into loops; (ii) compressive strain (in SiGe) enhances the transformation of $\{311\}$ s into loops; (iii) in all cases, the overall defect stability is not strongly modified in the presence of strain. The observed results are discussed in terms of the various mechanisms involved, including the increase of the interstitial diffusivity in relaxed SiGe alloys (with respect to $\mathrm{Si}$ ) and the strain effects on both interstitial equilibrium concentration and defect formation energy.
\end{abstract}

\section{Introduction}

The fabrication of pseudomorphic SiGe source/drain regions on $\mathrm{Si}$ substrates has attracted more and more attention over the last years due to the possibility of inducing tensile strain in Si MOSFETs to enhance carrier mobility in the channel [1]. The optimization of the performances of these devices relies on the capability to accurately model implantation and diffusion phenomena in the SiGe regions, which are strongly related to the evolution of implantation-induced extended defects $[2,3]$. The effects of Germanium composition on the evolution of extended defects in Si-Ge layers has already been reported in literature by several publications [4-6]. Fedina et al. [6] showed that differently from silicon, the formation of dislocation loops in electron irradiated strained SiGe layers was favoured in comparison with planar $\{311\}$ defects, due to the presence of strain in the SiGe layer. A similar effect has lately been reported in the case of extended defects formed by ion implantation in unstrained SiGe layer $^{5}$, where it is shown that the concentration of Ge in the alloy not only affects the $\{311\} /$ Dislocation Loops density ratio but also the ripening of these two kinds of defects.

To be able to disentangle the different mechanisms contributing to the modification of defect evolution in SiGe epitaxial layers, the "chemical" contribution due to the presence of $\mathrm{Ge}$ and the contribution due to the presence of strain must be studied separately, and in easily comparable structures. For this reason, in this work, we will report a series of TEM observations on a suitable set of test-structures, including both strained and unstrained Si and SiGe layers of different compositions, to investigate the evolution of extended defects after an amorphising implant. The results will be discussed in terms of the energetics of extended defects and of the interstitials diffusivity.

\section{Experimental details}

For the compositional effect study, three wafers containing relaxed SiGe alloy layers with various Ge contents (20, 35 and 50 at.\%) were grown by CVD on graded SiGe virtual substrates. For the study of strain effects, two more wafers were fabricated. In the first, a $40 \mathrm{~nm}$ tensely strained $\mathrm{Si}$ layer was grown on relaxed $\mathrm{Si}_{0.8} \mathrm{Ge}_{0.2}$ layer, which was followed by the deposition of a $50 \mathrm{~nm} \mathrm{Si}{ }_{0.8} \mathrm{Ge}_{0.2}$ capping layer. In the second, a $40 \mathrm{~nm}$ compressively strained $\mathrm{Si}_{0.8} \mathrm{Ge}_{0.2}$ layer was directly grown on top of a Si substrate, followed by a $50 \mathrm{~nm}$ Si capping 
Table 1

Details of the annealing conditions for the various samples used in this study. All samples were implanted with $35 \mathrm{keV} \mathrm{Ge}^{+}$ions to a dose of $1 \times 10^{15} \mathrm{~cm}^{-2}$.

\begin{tabular}{|c|c|c|c|c|c|c|c|}
\hline \multicolumn{2}{|c|}{ Anneals } & \multicolumn{4}{|c|}{ Relaxed $\mathrm{Si}_{1-x} \mathrm{Ge}_{x}$ alloys } & \multicolumn{2}{|c|}{ Strained structures } \\
\hline$T\left({ }^{\circ} \mathrm{C}\right)$ & $t(\mathrm{~s})$ & $x=0$ & $x=0.2$ & $x=0.35$ & $x=0.5$ & sSi (tensile) & sSiGe (compr.) \\
\hline \multirow[t]{2}{*}{680} & 300 & $\prec$ & $\prec$ & 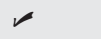 & $\prec$ & & \\
\hline & 900 & $\nu$ & $\swarrow$ & $r$ & $\prec$ & & \\
\hline \multirow[t]{2}{*}{740} & 300 & $\swarrow$ & $\checkmark$ & & & $\checkmark$ & $\swarrow$ \\
\hline & 900 & $\swarrow$ & $\boldsymbol{r}$ & & & $\swarrow$ & $\swarrow$ \\
\hline \multirow[t]{2}{*}{800} & 30 & $\boldsymbol{V}$ & 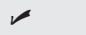 &  & $\swarrow$ & $\prec$ & $\prec$ \\
\hline & 300 & $\checkmark$ & 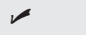 & $\boldsymbol{r}$ & 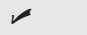 & $\swarrow$ & 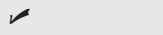 \\
\hline
\end{tabular}

layer. All wafers were amorphised to a depth of about $60 \mathrm{~nm}$ (cf. Table 1). $2 \times 2 \mathrm{~cm}^{2}$ pieces were then cut from each wafer and annealed at different temperatures, as described in Table 1.

All samples were analysed by Transmission Electron Microscopy (TEM) in a JEOL 2010-HC microscope, following a standard specimen preparation technique (mechanical and dimple grinding followed by PIPS ion-milling). Weak Beam Dark Field (WBDF) analysis [7] has been used in both cross-section and plan view specimens to measure defects density, size and position. All plan-view observations have been carried out using $\mathbf{g}=$ [220], $\mathbf{g}=$ [400] and $\mathbf{g}=$ [422] imaging conditions which are particularly adapted to differentiate between defects with similar shapes and different Burgers vectors (as is the case of $\{311\}$ defects and rod-like \{111\}s) [8]. The quantitative analysis of extended defect populations is based on a method described in Refs. $[9,10]$, that allows, in particular, to calculate the density of interstitial atoms trapped in the extended defects from the measured values of the defect density and defect size. In addition, for this work, a semi-automated defect counting procedure has been developed based on image manipulation programs, such as ImageJ [11], and Matlab [12] scripts.

\section{Results and discussion}

\subsection{Preliminary observations}

We initially run preliminary structural analysis on all structures in order to verify the layers thicknesses, the presence of defects due to partial relaxation, the strain value in the layer (for strained layers) and the position of the extended defects created by the implant. WBDF TEM observations of the three relaxed SiGe layers in cross-section (not shown) indicate that relaxation defects are located only in the deep graded layer, confirming that the top SiGe layer is totally relaxed and free from defects. Similarly, no relaxation defects were observed in the zones of interest of the two strained $\mathrm{Si}$ and SiGe structures. In addition, the deformation of the strained layers has been measured in both strained structures using two different techniques: Geometrical Phase Analysis(GPA) [13] and Dark-field electron-holography [14]. In both cases, it was found that the lattice mismatch between the strained layers and their respective bottom layers in a direction parallel to their interface is negligible. Finally, the depth of the EOR defects formed after the amorphising implant and anneal was measured for all the investigated structures and found to be equal to $\sim 65 \mathrm{~nm}$, independently of the Ge content or the strain in the layer. This suggests that any variation of the amorphous thickness when passing from pure Si to SiGe alloys up to $50 \%$ is lower than the TEM experimental errors. An example is shown in Fig. 1 for the reference Si wafer (a), the relaxed $\mathrm{Si}_{0.5} \mathrm{Ge}_{0.5}$ (b) and the strained $\mathrm{Si}_{0.8} \mathrm{Ge}_{0.2}$ wafer (c).

\subsection{Compositional effects}

Fig. 2 shows a visual summary of the evolution of extended defects in the three relaxed SiGe structures after anneal at $800{ }^{\circ} \mathrm{C}$ for $30 \mathrm{~s}$. The WBDF image taken from the Si specimen (Fig. 2a) shows that the
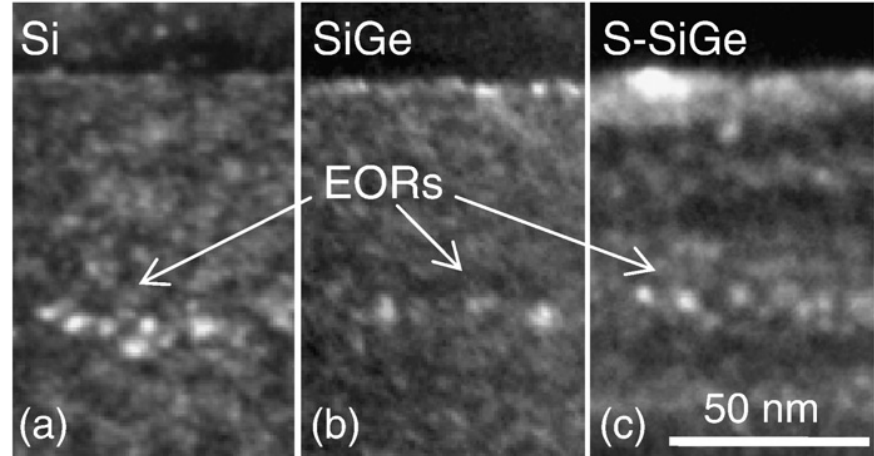

Fig. 1. Cross-section WBDF images of various samples showing the position of the EOR defects after implantation with $35 \mathrm{keV} \mathrm{Ge}+1 \times 10^{15} \mathrm{~cm}^{-2}$ and annealing at $680^{\circ} \mathrm{C}$. (a) Bulk Si. (b) Relaxed $\mathrm{Si}_{0.5} \mathrm{Ge}_{0.5}$ wafer. (c) Compressively strained $\mathrm{Si}_{0.8} \mathrm{Ge}_{0.2}$ wafer.

majority of defects are $\{311\}$ s appearing as rod-like bright-contrast lines. Some Faulted Dislocation Loops (FDL) are also visible and appear in the image as elliptical non-uniform bright regions on a dark background (cf. arrows in Fig. 2a). In the $x=20 \%$ relaxed SiGe structure (Fig. 2b), the two types of defects are still visible but the size and density of $\{311\}$ s has decreased, while the density of FDLs has increased. This effect is more pronounced in the 35\% (Fig. 2c) and the $50 \%$ case (not shown), where the totality of defects consist of FDLs. It is important to note that when the apparent defect size is small, the rod-like shape of $\{311\}$ defects is difficult to detect and it is necessary to apply the defect visibility criteria on several WBDF images obtained using different diffracting vectors ([220], [400] and [422]) in order to determine their nature.

Fig. 3 reports the corresponding quantitative analysis of these samples (red squares), as well as of those annealed at $680^{\circ} \mathrm{C}$ for $300 \mathrm{~s}$ (green circles) and at $800{ }^{\circ} \mathrm{C}$ for $300 \mathrm{~s}$ (black triangles). The total density of interstitials trapped in all extended defects is reported on the upper plot as a function of the Ge content in the alloy. When complete defect dissolution has been achieved, i.e. no defects were observed in the microscope, we assumed an interstitial density value equal to the TEM detection limit, which is estimated at $\sim 1 \times 10^{8} \mathrm{~cm}^{-2}$. In the lower plot of Fig. 3, the fractions of interstitials contained in each defect type is reported: $\{311\}$ defects (empty symbols) and Loops (filled symbols). For an annealing at $680{ }^{\circ} \mathrm{C},\{311\}$ defects only are observed in all SiGe structures (empty circles in Fig. 3b), which trap a continuously decreasing density of interstitials when the Ge content increases (green circles in Fig. 3a), suggesting that in such case $\{311\}$ defects become more unstable. This effect is enhanced after a $800{ }^{\circ} \mathrm{C} 30 \mathrm{~s}$ anneal, where the total density of interstitials in the defects decreases of about 2 orders of magnitude from bulk Si to $\mathrm{Si}_{0.5} \mathrm{Ge}_{0.5}$ (cf. red squares in Fig. 3a). In addition, after such a higher
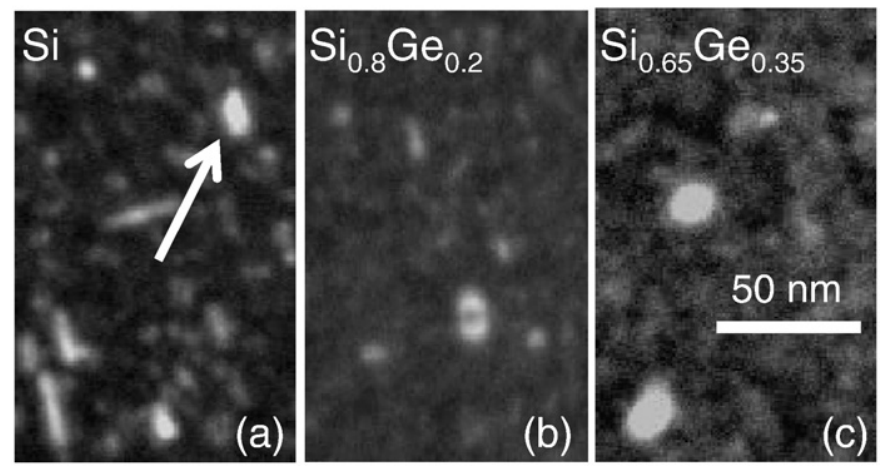

Fig. 2. Plan-view WBDF images of various samples showing the nature and density of EOR defects in relaxed structures with different Ge content after implantation with $35 \mathrm{keV} \mathrm{Ge}^{+} 1 \times 10^{15} \mathrm{~cm}^{-2}$ and annealing at $800{ }^{\circ} \mathrm{C}$ for $30 \mathrm{~s}$. (a) bulk $\mathrm{Si}$; (b) $\mathrm{Si}_{0.2} \mathrm{Ge}_{0.2}$; (c) $\mathrm{Si}_{0.35} \mathrm{Ge}_{0.35}$ 


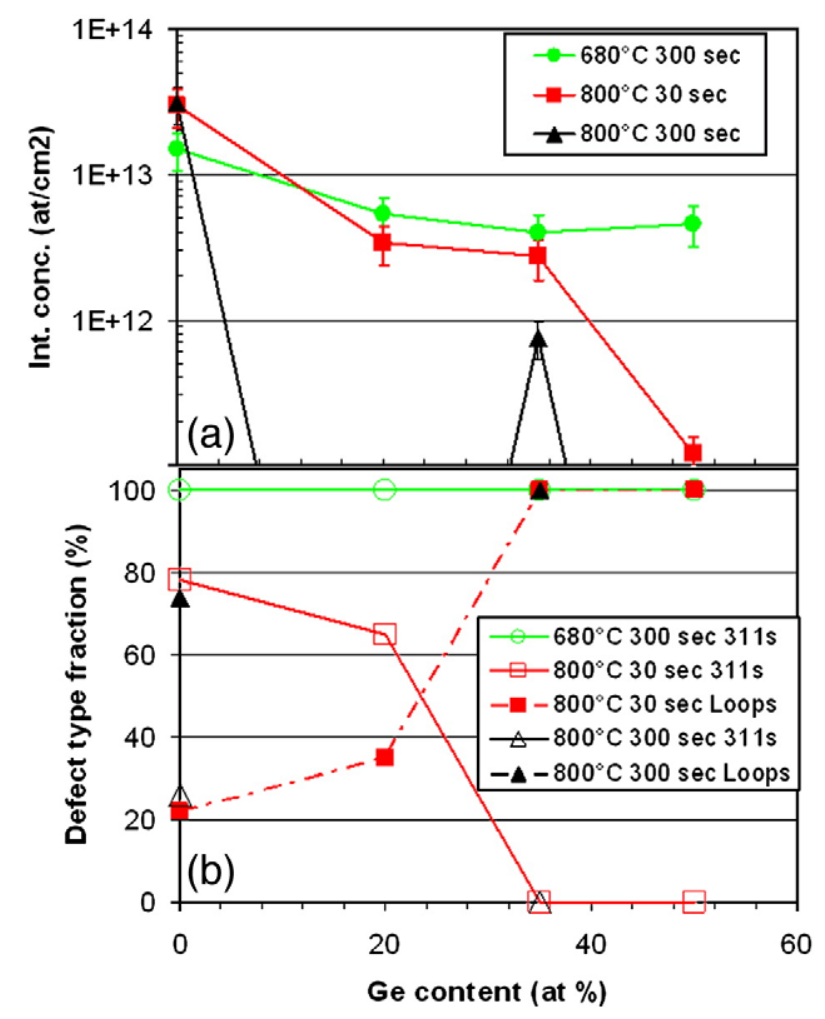

Fig. 3. Total density of interstitials contained in all extended defect families (a) and corresponding fractions contained in $\{311\}$ defects and loops (b) as a function of $\mathrm{Ge}$ content in relaxed SiGe structures after implantation with $35 \mathrm{keV} \mathrm{Ge}{ }^{+} 1 \times 10^{15} \mathrm{~cm}^{-2}$ and various annealing conditions.

thermal budget anneal, both $\{311\}$ defects and dislocation loops are observed in the reference bulk Si specimen. In this case, it is found that increasing the Ge content in the alloy leads to an enhanced transformation of $\{311\}$ defects into dislocation loops (cf. red squares in Fig. 3b). When the thermal budget is further increased $\left(800^{\circ} \mathrm{C}\right.$ 300 s, black triangles in Fig. 3), a faster kinetics of both effects due to increased Ge content (lower defect stability and enhanced \{311\}-toloop transformation) is expected. The first effect leads to a faster dissolution of all defects while, considering that loops are known to be energetically more stable than $\{311\}$ defects, the second effect is expected to slow down the dissolution process. The combined effect of both phenomena can therefore explain the apparently puzzling results obtained for this annealing condition: for a $20 \%$ SiGe alloy, the density of interstitials contained in loops was only $35 \%$ of the total after $30 \mathrm{~s}$. In this case, a longer anneal (300 s) leads to complete defect dissolution. Instead, for a Ge content of 35\%, the defect population entirely consists of loops already after $30 \mathrm{~s}$ (filled squares in Fig. 3b) which can therefore "survive" to the longer $300 \mathrm{~s}$ anneal. Finally, for a $\mathrm{Si}_{0.5} \mathrm{Ge}_{0.5}$ alloy, the total density of interstitials in the defects is already very low after $30 \mathrm{~s}$ at $800^{\circ} \mathrm{C}$, so that in this case a longer anneal inevitably leads to a full defect dissolution.

\subsection{Strain effects}

Fig. 4 shows a visual summary of the evolution of extended defects in the strained $\mathrm{Si}$ and $\mathrm{SiGe}$ structures after anneal at $740{ }^{\circ} \mathrm{C}$ for $900 \mathrm{~s}$. It is found that the $\{311\}$ defects exhibit a smaller size and a slightly higher density in the strained Si sample (Fig. 4a) compared to the reference one (Fig. 4c). In addition, while $\{311\}$ s represent the totality of the defect population in the strained sample, a small fraction of loops is present in the reference unstrained one (cf. arrow in Fig. 4a). These results suggest that the Ostwald ripening of $\{311\}$ defects is somehow weakly "retarded" by tensile strain, which is also respon-

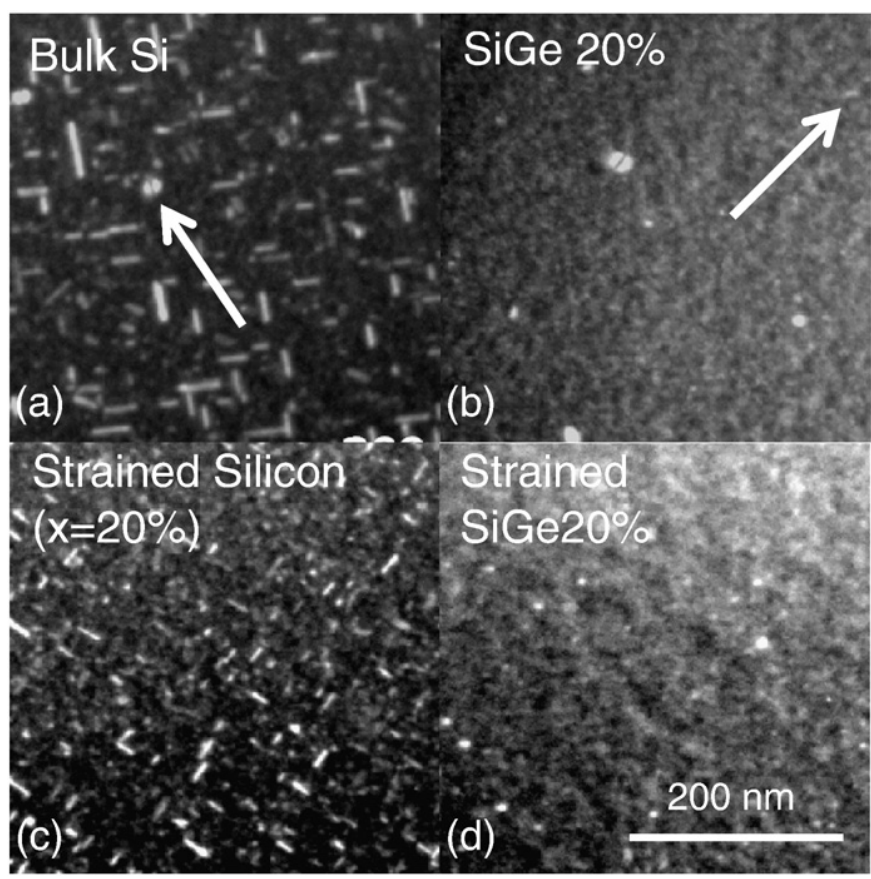

Fig. 4. Plan-view WBDF images of various samples showing the nature and density of EOR defects in relaxed and strained structures with different $G$ content after implantation with $35 \mathrm{keV} \mathrm{Ge}{ }^{+} 1 \times 10^{15} \mathrm{~cm}^{-2}$ and annealing at $740{ }^{\circ} \mathrm{C}$ for 900 s. (a) Bulk Si. (b) Relaxed $\mathrm{Si}_{0.2} \mathrm{Ge}_{0.2}$. (c) Strained silcon (tensile). (d) strained $\mathrm{Si}_{0.2} \mathrm{Ge}_{0.2}$ (compressive).

sible for a less effective $\{311\}$-to-loops transformation. The opposite behaviour is observed in the case of compressive strain introduced in SiGe layers: while some $\{311\}$ s are still present in the relaxed SiGe structure (cf. arrow in Fig. 4b), the compressively strained SiGe sample only contains loops. As in the previous case, the overall defect stability is not strongly altered, with the total density of interstitials contained in the defects being comparable in the two structures.

The quantitative analysis of the investigated samples confirms this behaviour. Fig. 5 reports the data relative to the samples annealed for $300 \mathrm{~s}$ at $740{ }^{\circ} \mathrm{C}$ (red circles) and $800{ }^{\circ} \mathrm{C}$ (black triangles). It is found that the major impact of tensile strain in $\mathrm{Si}$ is to slow down the transformation of $\{311\}$ s into loops (the fraction of interstitials in loops goes from $75 \%$ in $\mathrm{Si}$ down to $\sim 5 \%$ in sSi at $800{ }^{\circ} \mathrm{C}$, cf. filled triangles in Fig. 5b), while the total density of interstitials in the defects is not strongly affected (cf. Fig. 5a). In contrast, compressive strain in SiGe favours the formation of loops (from 65\% to 100\% at $740{ }^{\circ} \mathrm{C}$, cf. filled circles in Fig. 5b), with, again, a weak impact on the total density of interstitials in the defects.

\section{Discussion}

The evolution of an implantation-induced defect population during annealing is the result of several concomitant mechanisms, which in most cases are thermally activated, such as the diffusion of the free interstitials that compose the defects $\left(D_{i}\right)$, the interstitial capture from a given defect (related to the interstitial supersaturation, $C_{i} / C_{i}^{*}$ ), the emission of interstitials from a defect (related to its formation energy, $E_{f}$ ), the transformation of $\{113\}$ defects into dislocation loops (associated to an energy barrier that limits the transformation) and the recombination of interstitials, diffusing out of the defect region, at the wafer surface. A satisfactory explanation of the impact of Ge content (in relaxed SiGe structures) and strain on the defect evolution requires a detailed study of the modification of each one of these mechanisms in strained and relaxed SiGe alloys. Although this is beyond the scope of this paper, we tentatively suggest that the modification of the interstitial diffusivity is the most critical parameter to explain the Ge composition effects observed in relaxed SiGe alloys. Indeed, several studies [15-17] indicate that both Ge 




Fig. 5. Total density of interstitials contained in all extended defect families (a) and corresponding fractions contained in $\{311\}$ defects and loops (b) for various relaxed and strained structures with different Ge content after implantation with $35 \mathrm{keV} \mathrm{Ge}^{+}$ $1 \times 10^{15} \mathrm{~cm}^{-2}$ and different annealing conditions.

and Si self-diffusivities in relaxed SiGe strongly increase with Ge content (i.e. by a factor of $\sim 300$ from $\mathrm{Si}$ to $\mathrm{Si}_{0.5} \mathrm{Ge}_{0.5}$ at $900{ }^{\circ} \mathrm{C}$ ). This leads to an enhanced interstitial recombination at the surface during defect evolution and to an accelerated defect growth. In the case of $\{311\}$ defects, this also implies that the critical size for transformation into loops [18] is reached more quickly in SiGe alloys than in Si. These modifications are in agreement with both observed effects in relaxed SiGe structures: (i) an overall decrease of the defect stability (i.e. a decrease in the total density of interstitials contained in the defects) and (ii) an enhanced \{311\}-to-loops transformation. On the other hand, concerning the effect of strain, theoretical studies [19] indicate that biaxial tensile (compressive) strain in $\mathrm{Si}$ induces an increase (decrease) of the interstitial diffusivity. This is apparently in contrast with the observed effects in tensely strained $\mathrm{Si}$, where the "slower" defect ripening with respect to unstrained Si (higher \{311\}s density and smaller size) is rather in agreement with a lower interstitial diffusivity. A more complex scenario is therefore required to fully explain these results, possibly including the strain effects on both interstitial equilibrium concentration and defect formation energy.

\section{Conclusions}

In this work we have studied the evolution of extended defects in relaxed and strained $\mathrm{Si}$ and SiGe structures after an amorphising implant, in order to separately investigate composition and strain effects on defect ripening. The general conclusions of our experimental observations can be summarised as follows:

- composition effects: the increase of Ge concentration in relaxed SiGe structures leads to (i) an overall decrease of the defect stability (i.e. a decrease in the total density of interstitials contained in the defects) and to (ii) an enhanced \{311\}-to-loops transformation.

- Strain effects: ( $i$ ) Tensile strain (in Si) retards the transformation of \{311\} defects into loops; (ii) compressive strain (in SiGe) enhances the transformation of \{311\}s into loops; (iii) in all cases, the overall defect stability is not strongly modified in the presence of strain.

We suggest that the increase of the interstitial diffusivity in SiGe (compared to $\mathrm{Si}$ ) is the main mechanism responsible for the observed effects in relaxed SiGe. A more complex scenario, taking into account several contributing mechanisms, is instead needed to fully explain the observed effects in strained $\mathrm{Si}$ and SiGe structures, possibly including the strain effects on both interstitial equilibrium concentration and defect formation energy.

\section{Acknowledgments}

This work was funded by the EU project ATOMICS (STREP 027152).

\section{References}

[1] C. Claeys, E. Simoen (Eds.), Germanium-Based Technologies: From Materials to Devices, Elsevier, 2007.

[2] S.C. Jain, W. Schoenmaker, R. Lindsay, P.A. Stolk, S. Decoutere, M. Willander, H.E. Maes, J. Appl. Phys. 91 (2002) 8919.

[3] S. Uppal, A.F.W. Willoughby, J.M. Bonar, A.G.R. Evans, N.E.B. Cowern, R. Morris, M.G. Dowsett, J. Appl. Phys. 90 (2001) 4293.

[4] S. Im, J. Washburn, R. Gronsky, N.W. Cheung, K.M. Yu, Appl. Phys. Lett. 63 (1993) 929.

[5] R.T. Crosby, K.S. Jones, M.E. Law, L. Radic, P.E. Thompson, Appl. Phys. Lett. 87 (2005) 192111.

[6] L. Fedina, O.I. Lebedev, G. Van Tendeloo, J. Van Landuyt, O.A. Mironov, E.H. Parker, Phys. Rev. B. 61 (2000) 10336.

[7] D.B. Williams, C.B. Carter, Transmission Electron Microscopy-A Textbook for Materials Science, Springer, 1996

[8] S. Boninelli, N. Cherkashin, A. Claverie, F. Cristiano, Appl. Phys. Lett. 89 (2006) 161904

[9] F. Cristiano, J. Grisolia, B. Colombeau, M. Omri, F. Giles, B. de Mauduit, A. Claverie, J. Appl. Phys. 87 (2000) 8420.

[10] A. Claverie, B. Colombeau, B. de Mauduit, C. Bonafos, X. Hebras, G. Ben Assayag, F. Cristiano, Appl. Phys. A 76 (2003) 1025.

[11] Image], http://rsbweb.nih.gov/ij/.

[12] Mathwork Matlab, http://www.mathworks.com/.

[13] M. Hÿtch, J.L. Putaux, J. Thibault, Phil. Mag. 86 (2006) 4641

[14] M. Hÿtch, F. Houdellier, F. Hue, E. Snoek, Nature 453 (2008) 1086

[15] N.R. Zangenberg, J. Lundsgaard Hansen, J. Fage-Pedersen, A. Nylansted Larsen, Phys. Rev. Lett. 87 (2001) 125901.

[16] A. Strohm, T. Voss, W. Frank, J. Räisänen, M. Dietrich, Physica B 308 (2001) 542.

[17] H. Bracht, E.E. Haller, R. Clark-Phelps, Phys. Rev. Lett. 81 (1998) 393.

[18] F. Cristiano, N. Cherkashin, X. Hebras, P. Calvo, Y. Lamrani, E. Scheid, B. de Mauduit, A. Claverie, B. Colombeau, W. Lerch, S. Paul, Nucl. Inst. and Meth. B 216 (2004) 46

[19] M. Diebel et S.T. Dunham, Proc. of Int. Conf. on Simul. of Semic. Proc. and Dev. (SISPAD) 2003, IEEE (2003) p.147-150. 